\title{
LIBERDADE DE IMPRENSA \\ E INTANGIBILIDADE MORAL DO INDIVÍDUO
}

GRACE KELLY SAMPAIO 


\section{LIBERDADE DE IMPRENSA E INTANGIBILIDADE MORAL DO INDIVÍDUO}

Grace Kelly Sampaio ${ }^{1}$

\section{RESUMO}

0 presente artigo traz um breve estudo sobre o direito à indenização de dano moral resultante de publicação de matéria jornalística, tendo em mira o aparente conflito de normas entre os preceitos constitucionais que garantem o direito à intangibilidade moral do indivíduo e, ao mesmo tempo, asseguram a livre manifestação do pensamento, de idéias e a liberdade de imprensa. Para dirimir esse conflito, doutrina e jurisprudência pátrias norteiam-se por três principais entendimentos: a) preponderam os direitos da personalidade (intimidade, vida privada, honra, dignidade pessoal), em qualquer circunstância; b) tem preferência a liberdade de imprensa e de informar; c) diante do conflito, deve-se proceder à conciliação das normas sem perder de vista as circunstâncias do caso concreto, de modo que possam subsistir cada um desses direitos fundamentais. A meu ver a última dessas correntes é a que melhor soluciona o conflito entre os direitos da personalidade e a liberdade de informar. Os direitos da personalidade e o direito à livre manifestação do pensamento e de idéias, que abrange também a liberdade de imprensa, proclamados no art. 5ำ, da Constituição Federal, são igualmente fundamentais, não havendo hierarquia entre eles. Em função do caráter relativo que possuem, esses direitos não guarda m subordinação entre si, devem somar-se e harmonizar-se reciprocamente, conforme as circunstâncias que delinearem o conflito em cada caso concreto. Diante de um conflito entre tais direitos, o intérprete deve harmonizá-los à luz das demais normas contidas na Constituição, verificando no caso concreto se a notícia veiculada pela imprensa é verdadeira, se se limitou a informar, se houve abuso no exercício do direito de liberdade de

\footnotetext{
${ }^{1}$ Graduada em Direito, pós-graduanda do Curso de Direito Constitucional da UNITINS.
} 
informar e se daí resultou prejuízo a algum dos direitos da personalidade, como a privacidade, a intimidade, a honra e a imagem da pessoa. Essa a melhor alternativa para se obter a solução mais justa.

\section{Palavras-chave:}

intangibilidade moral do indivíduo, liberdade de imprensa, conflito aparente de normas, indenização.

\section{RESUMEN}

El presente artículo trae un breve estudio sobre el derecho a la indemnización del daño moral resultante de publicación de materia periodística, enfocando el aparente conflicto de normas entre los preceptos constitucionales que garantizan el derecho a la intangibilidad moral del individuo y, al mismo tiempo, aseguran la libre manifestación del pensamiento, de ideas y la libertad de prensa. Para dirimir ese conflicto, doctrina y jurisprudencia patrias son orientadas por tres principales entendimientos: a) preponderan los derechos de la personalidad (intimidad, vida privada, honor, dignidad personal), en cualquier circunstancia; b) tiene preferencia la libertad de prensa y de informar; c) delante del conflicto, se debe proceder a la conciliación de las normas sin dejar de mirar las circunstancias del caso concreto, de modo que puedan sustituir cada uno de los derechos fundamentales. En mi opinión la última de esas corrientes es la que mejor resuelve el conflicto entre los derechos de personalidad y la libertad de informar. Los derechos de personalidad y el derecho a la libre manifestación del pensamiento y de ideas, que cubre también la libertad de prensa, proclamados en el art.

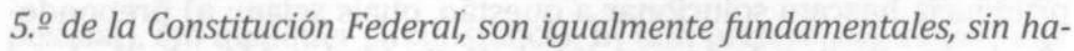
ber jerarquías entre ellos. En función del carácter relativo que poseen, esos derechos no guardan subordinación entre si, debiendo sumarse y armonizarse recíprocamente, según las circunstancias que delineen el conflicto en cada caso concreto. Delante de un conflicto entre tales derechos, el intérprete deber armonizarlos a la luz de las demás normas contenidas y la Constitución, verificando en el caso concreto si la noticia vehiculada por la prensa es verdadera (real), si se limitó a informar, 
si hubo abuso en el ejercicio del derecho de libertad de informary si de ahí resultó perjuicio a alguno de los derechos de personalidad, como la privacidad, la intimidad, el honor y la imagen de la persona. Esa es la mejor alternativa para obtenerse la soluciỏn más justa.

\section{Palabras-clave:}

intangibilidad moral del individuo, libertad de prensa, conflicto aparente de normas, indemnización.

\section{INTRODUÇÃo}

0 crescente número de demandas indenizatórias por dano moral contra empresas jornalísticas leva à análise de uma questão: como dirimir o conflito que se estabelece em tais ações diante do confronto entre os direitos à intangibilidade moral do indivíduo (direitos da personalidade) e o direito à livre manifestação do pensamento e idéias (que abrange também a liberdade de imprensa), ambos direitos fundamentais proclamados no art. $5^{\circ}$ da Constituição Federal? Até que ponto uma empresa de jornalismo pode invadir a intimidade ou privacidade de alguém divulgando fatos gravosos à honra $\mathrm{e}$ à dignidade dessa pessoa?

No presente trabalho pretende-se examinar qual o melhor critério de interpretação para dirimir esse conflito aparente de normas.

Para tanto serão analisados, inicialmente e de forma sintética, três dos principais entendimentos através dos quais doutrina e jurisprudência buscam solucionar a questão, quais sejam: a) preponderância dos direitos da personalidade (intimidade, vida privada, honra, dignidade pessoal), em qualquer circunstância; b) preferência à liberdade de imprensa e de informar; c) conciliação das normas sem perder de vista as circunstâncias do caso concreto, de modo que possa subsistir cada um desses direitos fundamentais.

Diante do estudo mais detido da corrente doutrinária e jurisprudencial que adota o critério da conformação das normas constitucio- 
nais aparentemente em conflito, tendo em mira as particularidades de cada caso concreto, serão examinados os limites do direito à liberdade de informação e de imprensa, os limites do direito à intangibilidade moral do indivíduo e a "teoria da proteção débil à honra de homens públicos."

Verificar-se-á que o direito de informar é tão essencial para o aprimoramento do Estado democrático de direito como a preservação da incolumidade moral do indivíduo, bem assim que não existe hierarquia ou subordinação entre os direitos da personalidade e a liberdade de manifestação do pensamento, de idéias e de imprensa, de tal sorte que a melhor solução para dirimir conflitos entre tais direitos consiste em harmonizá-los, conformando-os à demais normas contidas na Constituição à vista das circunstâncias do caso concreto.

\section{DESENVOLVIMENTO}

A análise acerca do cabimento ou não de indenização por danos morais em decorrência de veiculação de matéria jornalística põe em confronto dois direitos fundamentais proclamados no art. $5^{\circ}$ da Constituição Federal: o direito à intangibilidade moral do indivíduo (direitos da personalidade) e o direito à livre manifestação do pensamento e de idéias (que abrange também a liberdade de imprensa).

Para dirimir esse conflito, doutrina e jurisprudência pátrias norteiam-se por três principais entendimentos: a) preponderam os direitos da personalidade (intimidade, vida privada, honra, dignidade pessoal), em qualquer circunstância; b) tem preferência a liberdade de imprensa e de informar; c) diante do conflito, deve-se proceder à conciliação das normas sem perder de vista as circunstâncias do caso concreto, de modo que possam subsistir cada um desses direitos fundamentais.

Filio-me à corrente doutrinária e jurisprudencial que adota o terceiro critério de interpretação acima citado, qual seja, a conformação das normas constitucionais em conflito tendo em mira as circunstân- 
cias de cada caso concreto.

Se por um lado a preservação da incolumidade moral do indivíduo constitui-se inestimável conquista da sociedade, que a passos lentos vem afastando-se dos tempos de barbárie escancarada ou velada, de outra banda é inconteste que foi e é através da liberdade de imprensa e da liberdade de expressão que a sociedade alcançou importantes vitórias sociais como contra a impunidade, a corrupção e a ditadura.

A primazia total aos valores morais, em detrimento da efetiva necessidade de manter a sociedade bem informada sobre fatos que lhe dizem respeito, não só prejudica o aperfeiçoamento do Estado democrático de direito, como acarreta abominável retrocesso nas conquistas sociais. 0 prestígio ilimitado à informação, sem considerar valores morais como a honra, a privacidade, a intimidade e a imagem, pode gerar uma sociedade frívola, egoísta e cruel.

Ultrapassar os limites da liberdade alheia vulnera o bem-estar individual e social. É necessário que a liberdade sofra limites a fim de que a vida em sociedade se desenvolva em paz e harmonia. "Por mais estranho que possa parecer, paradoxal até, a manutenção da liberdade está intrinsecamente ligada à sua limitação"2.

A história dos direitos fundamentais, dentre os quais se situam o direito à liberdade de manifestação do pensamento e o direito à intangibilidade moral, está ligada à história da limitação do poder decorrente do reconhecimento e proteção da dignidade da pessoa humana e dos direitos fundamentais do homem.

Como as normas aparentemente conflitantes tratam de direitos fundamentais, proclamados no art. 5을 da Constituição Federal, entre elas não pode haver hierarquia ou subordinação. Em um Estado democrático não existem direitos absolutos. A cada direito corresponde um dever que o relativiza. No que diz respeito ao exercício do direito

${ }^{2}$ SANTOS, Antônio Jeová. Dano Moral Indenizável. São Paulo: Revista dos Tribunais. 4a ed, 2003, p. 306. 
de liberdade de manifestação do pensamento, de idéias e da imprensa, o dever correspondente consiste na obrigação de bem informar, ou seja, de veicular notícias verdadeiras, exatas, sem agravo à honra ou à dignidade do indivíduo, de acordo com a realidade.

Antônio Jeová Santos observa, com propriedade, que:

O lugar-comum, na direção de que os direitos da personalidade têm maior proteção, porque superior à liberdade de manifestação de pensamento, não merece consideração porque, no Brasil, ambos direitos encontram-se no Capítulo atinente à liberdade fundamental, art. 5ㅇ, incs. IV e X. Nem é possível aceitar a tese de que a liberdade de imprensa deve ser exercida de forma absoluta, porque o exercício de qualquer direito há de ser feito sem exagero ou abuso. ${ }^{3}$

Sobre o tema, Gregório Badeni, em inspirada síntese, esclarece:

Em sua dimensão individual, a liberdade de imprensa se exerce com o único propósito de satisfazer, em forma pública, a necessidade que tem o indivíduo de expressar seu pensamento. Ademais, essa expressão do pensamento carece de conotação institucional, de significativa relevância para o interesse público. Neste âmbito, o exercício da liberdade de imprensa, por tratar-se de uma das espécies do gênero liberdade, está situada em um plano de igualdade com as restantes liberdades individuais do homem. Quem a exerce, não pode desfrutar de um tratamento jurídico preferencial, porque todas as liberdades individuais, como elementos que configuram a dignidade humana, estão em plano de igualdade, sem que seja viável estabelecer uma escala hierárquica para elas. ${ }^{4}$

A liberdade de imprensa não foi instituída pela Constituição em benefício exclusivo dos indivíduos que publicam suas idéias, tam-

\footnotetext{
${ }^{3}$ SANTOS, Antônio Jeová. Dano Moral Indenizável. São Paulo: Revista dos Tribunais. 4⿳⺈冂a ed, 2003, p. 306.

${ }^{4}$ Idem, apud, p. 307.
} 
pouco se esgota como exercício individual. Constitui-se, segundo Gregório Badeni, num "instrumento indispensável para consolidar as restantes liberdades, e permitir o desenvolvimento de uma vida democrática integral, com todas suas virtudes e defeitos, que não são próprios do sistema, mas conseqüência da conduta dos homens." ${ }^{\text {5 }}$

Diante de um conflito entre os direitos da personalidade e o direito à livre manifestação do pensamento e de idéias, que abrange também a liberdade de imprensa, o intérprete deve harmonizá-los à luz das demais normas contidas na Constituição, confrontando as particularidades do caso concreto, evitando posicionamentos extremados, que de regra não refletem sabedoria.

No exercício dessa atividade de harmonizar as citadas normas constitucionais quando em colisão é mister que se verifique se a notícia veiculada pela imprensa é verdadeira, se se limitou a informar, se houve abuso no exercício do direito de liberdade de informar e se daí resultou prejuízo a algum dos direitos da personalidade, como a privacidade, a intimidade, a honra e a imagem da pessoa.

Como brilhantemente enunciou Isidoro Goldenberg:

Não existe um direito para lesionar a honra ou a intimidade através da imprensa, porque a liberdade de informar não é absoluta, mas está sujeita à responsabilidade pelos atos ilícitos que se cometem através dela, conforme o princípio constitucional de igualdade ante a lei. ${ }^{6}$

Quando ultrapassados os limites dentro dos quais a dignidade do homem deve ser protegida, seja pela consumação de um crime contra a honra, seja pela perturbação da privacidade ou intimidade resultante da atuação da imprensa, prevalecem os direitos personalíssimos relacionados à honra ou à intimidade e privacidade, dispondo a vítima de ações judiciais (cíveis ou criminais) para reprimir

\footnotetext{
${ }^{5}$ Apud SANTOS, Antônio Jeová. Dano Moral Indenizável. São Paulo: Revista dos Tribunais. $4^{\mathrm{a}} \mathrm{ed}$, 2003, p. 308.

${ }^{6}$ Ibidem, p. 309.
} 
quem abusou da liberdade de expressão.

Contudo, se constatado que no exercício do direito à liberdade de pensamento não houve qualquer abuso, se a notícia é verdadeira, despida de sensacionalismo, apresentada em linguagem correta, com razoabilidade e moderação, mesmo que tenha adentrado a esfera da vida privada de alguém não existirá ofensa à dignidade humana.

Só no estudo do caso concreto é que será possível concluir se ao divulgar a notícia o veículo de comunicação observou critérios de veracidade e de interesse público ou se agiu aviltando a dignidade humana.

Visando facilitar a definição dos limites da liberdade de manifestação do pensamento, a doutrina distingue dois principais fenômenos: a) liberdade de crônica ou de informar; b) liberdade de crítica ou de opinião.

No exercício da liberdade de crônica o jornalista e o veículo de comunicação ficam estritamente limitados pela veracidade, as notícias difundidas devem limitar-se a informar a comunidade sobre fatos de interesse geral, de modo objetivo e sério.

A liberdade de opinião ou de crítica dá ao jornalista e aos meios de imprensa maior liberdade de expressão, pois neste caso a publicação não cuida de fatos ocorridos, mas da opinião do jornal e do jornalista. Divide-se em liberdade de crítica stricto sensu, ou seja, liberdade de manifestar a opinião acerca de pessoas, fatos, instituições etc.; e liberdade de expressão de idéias, que consiste na liberdade de manifestação de convicções mais gerais, teses, doutrinas, concepções etc.

Guilherme Döring Cunha Pereira ensina que:

A crítica propriamente dita tem disciplina diversa daquela da crônica, como já salientado no capítulo 2 da $1^{\mathrm{a}}$ parte. A tradição dos sistemas jurídicos é de não requerer a prova da veracidade das opiniões, mas apenas a veracidade dos fatos. No que à crítica diz respeito, os requisitos de uma publicação legítima são: presença de interesse social e razoa- 
bilidade da forma. No que à crônica concerne, impõe-se ainda a presença do elemento veracidade?

Considera-se informação inverídica aquela eivada de falsidade ou erro. Falsa é a informação enganosa, fingida ou simulada com o fim de dar ao fato aparência bem diferente do que ocorreu na realidade, quando seu conteúdo não corresponde à verdade dos fatos. Além de informar o fato como verdadeiramente ocorreu, a imprensa tem ainda o dever de explicá-lo em seu contexto, em sua real significação. $\mathrm{Na}$ falsidade o informador age com dolo ou má-fé, consciente e deliberadamente com o fim de enganar.

Antônio Jeová Santos anotou, com acuidade:

A obrigação do órgão de comunicação é informar verazmente. Mesmo que a notícia seja verdadeira, atua de forma antijurídica o meio de comunicação que distorce notícia e a coloca ante o público de forma tendenciosa, ou omite aspectos relevantes ou destacando situações que não são notícias em si, mas que a finalidade é permeada da vontade de causar impacto sensacionalista, de tal maneira que o conteúdo da informação afete a honra ou a intimidade. "O desvirtuamento deliberado, ou mesmo decorrente de negligência da notícia veiculada, submete o periódico à responsabilidade pelos danos que porventura possam causar a terceiros." Nem se alegue que essa restrição na conduta da imprensa fere o princípio constitucional da livre expressão e manifestação de pensamento, apenas imputa-lhe a responsabilidade pelas conseqüências desse exercício, o que é outra coisa, decidiu o Tribunal de Justiça de São Paulo em acórdão da lavra do Des. Linneu Carvalho, publicada na RT, vol. 739, p. $275 .^{8}$

O erro na informação, por sua vez, resulta de um conceito equivo-

\footnotetext{
${ }^{7}$ Apud MAIA, Lauro Augusto Moreira. Novos Paradignas do Direito Civil. Curitiba: Juruá, 2007, p. 143.

${ }^{8}$ SANTOS, Antônio Jeová. Dano Moral Indenizável. São Paulo: Revista dos Tribunais. 4ª ed, 2003, p. 312 .
} 
cado que, na mente do informante, é diferente da realidade. Quando o informante incorre em erro ele não o faz conscientemente, age de boa-fé.

0 dever de veracidade é um dever de diligência, de tal sorte que não se admite responsabilidade sem culpa (objetiva). Tão-só o fato de a informação de notícia não ser verdadeira não gera responsabilidade. A obrigação de indenizar está subordinada à existência de culpa ou dolo do jornalista ou do órgão de comunicação, que só se eximirão da responsabilidade de indenizar se restar provado que agiram com diligência, sem dolo ou culpa.

Esse o regramento contido no art. 49 da Lei 5.250/67 (Lei de Imprensa), verbis: "Aquele que no exercício da liberdade de manifestação do pensamento e de informação, com dolo ou culpa, viola direito, ou causa prejuízo a outrem, fica obrigado a reparar".

Embora para a tipificação dos crimes de calúnia, difamação e injúria seja imprescindível a presença de dolo, uma vez que tais crimes não existem na forma culposa, para a caracterização da responsabilidade civil a ofensa à honra pode ser tanto a título de dolo (vontade deliberada de ofender) como de culpa pela difusão ou publicação de notícia sem as cautelas necessárias para confirmar se ela é verdadeira (negligência e imprudência).

Nesse sentido a jurisprudência:

Reportagens publicadas em jornal envolvendo o autor como participante de crime de extorsão - fato inverídico e evidenciado no próprio auto de prisão em flagrante nos co-autores do delito - negligência manifesta das rés - nexo causal configurado - princípio da informação responsável violado [...].

- ocorreu violação ao princípio da informação responsável. Ausência de autopoliciamento na redação e divulgação das denúncias envolvendo o autor sem uma melhor constatação dos acontecimentos. Caracterizou-se culpa grave pela negligência manifesta das rés [...] (TJPR, Ap. Cível 49.116.100, $4^{\text {a }}$ 
C. Cível, Rel. Juiz Lauro Laertes de Oliveira).

No que tange a pessoas que exercem vida pública, como políticos, artistas, atletas e outros que se mantêm em contato com o público, vem-se difundindo a "doutrina da debilidade da honra de homens públicos", segundo a qual se admite a redução dos limites da privacidade para, independentemente da anuência da pessoa envolvida, possibilitar a revelação de fatos de interesse público.

Pela natureza das atividades que livremente escolheram, as pessoas dotadas de notoriedade ou que exercem vida pública expõem-se a um controle mais rígido da sociedade, sujeitando-se a uma maior investigação e opinião públicas, de tal sorte que a proteção à honra delas dá-se de modo menos intenso, menos rigoroso, mais débil do que a proteção concedida aos particulares.

A professora Matilde Zavala de Gonzalez, citada por Antônio Jeová Santos, expõe alguns motivos que justificam a proteção débil da honra do homem público, dos quais destaco os principais:

a) a preservação do direito de crítica, como essencial ao sistema republicano;

b) a freqüente operatividade de interesses gerais prioritários, que justificam o que poderia ser ofensa contra a honra de pessoas que têm sob seu encargo transcendentes compromissos comunitários;

c) a aceitação de uma função pública traz em si uma tácita submissão à crítica das demais pessoas. 0 sujeito se coloca em uma vitrina sujeita a inspeção e controle pelos interessados na administração dos assuntos da sociedade. A função pública oferece um flanco inevitável à supervisão e possíveis ataques a seus afazeres. Trata-se de assumir o risco, sendo previsível a crítica, inclusive aquela que pareça injusta. ${ }^{9}$

\footnotetext{
9 SANTOS, Antônio Jeová. Dano Moral Indenizável. São Paulo: Revista dos Tribunais. 4ª ed, 2003, p. 331 .
} 
A doutrina da proteção débil, entretanto, não permite que a crônica ou a crítica ao homem público ultrapassem os limites da intimidade ou descambem para aleivosias. A divulgação de fatos íntimos, vida familiar, amigos etc. da pessoa pública, capazes de causar transtornos, só se justifica se essencial para o entendimento de um fenômeno histórico. A crítica, de sua parte, pode ser desagradável e até mesmo injusța, porém sem manifestar ataques desproporcionais ou desarrazoados, além disso, deverá ficar adstrita ao comportamento público ou social da pessoa que exerce atividade pública.

\section{CONCLUSÃO}

Neste trabalho procurou-se analisar o conflito aparente de normas entre dois direitos fundamentais proclamados no art. 50 da Constituição Federal: o direito à intangibilidade moral do indivíduo de um lado, e o direito à livre manifestação do pensamento, de idéias e liberdade de imprensa de outro.

Como visto, não existe hierarquia entre os direitos da personalidade e a liberdade de manifestação do pensamento e de idéias. 0 direito de informar é tão essencial para o aprimoramento do Estado democrático de direito como a preservação da incolumidade moral do indivíduo, conquistada lentamente a custo de muito suor e sangue.

Assim, a melhor solução diante de um conflito entre tais direitos está em harmonizá-los, conformando-os às demais normas contidas na Constituição e verificando, à luz do caso concreto, se houve abuso da liberdade de informar e se daí resultou prejuízo a algum dos direitos da personalidade, de modo que possa subsistir cada um desses direitos fundamentais contrapostos.

Como em um Estado democrático não existem direitos absolutos, o direito de liberdade de manifestação do pensamento, de idéias e de imprensa é relativizado pelo correspondente dever de bem informar, ou seja, de veicular notícias verdadeiras, exatas, sem agravo à honra ou à dignidade do indivíduo, de acordo com a realidade. 
Constatando-se abuso do direito à liberdade de pensamento, por afronta aos deveres inerentes ao exercício desse direito, configurarse-á ofensa à dignidade humana, dispondo a vítima de ações judiciais (cíveis ou criminais) para ressarcir-se dos danos materiais ou morais que sofreu e reprimir quem abusou da liberdade de expressão.

\section{REFERÊNCIAS BIBLIOGRÁFICAS}

MAIA, Lauro Augusto Moreira. Novos Paradignas do Direito Civil. Curitiba: Juruá, 2007, p. 143.

SANTOS, Antônio Jeová. Dano Moral Indenizável. São Paulo: Revista dos Tribunais. 4⿳a e ed, 2003. 